\title{
A prolonged altered mental status: is it absence status epilepticus?
}

\author{
Osama S M Amin
}

Department of Neurology, Sulaimaniya General Teaching Hospital, Sulaimaniya City, Iraq

\section{Correspondence to} Dr Osama SM Amin dr.osama.amin@gmail.com
To cite: Amin OSM. BMJ Case Rep Published online: [please include Day Month Year] doi:10.1136/bcr-2013009845

\section{DESCRIPTION}

An 11-year-old girl was admitted to our acute and emergency department with a 12-h history of confusion and non-responsiveness. There was no fever or neck stiffness. The parents denied any history of head trauma. She was diagnosed with grand mal epilepsy at the age of 7 years and completed a 2-year course of oral sodium valproate. The patient's mother stated that for the last 2 years she was seizure-free. Routine blood tests, toxicology screen, 12-lead ECG and CT brain scanning were unremarkable. Therefore, she was diagnosed with acute psychosis. However, her EEG is shown in figure 1. Intravenous diazepam of $0.2 \mathrm{mg} / \mathrm{kg}$ resulted in a profound improvement; note the abrupt termination of the typically symmetrical generalised $3 \mathrm{~Hz}$ spike-and-wave discharges (figure 2).

Absence status epilepticus (ASE) is a form of non-convulsive status epilepticus (NCSE). Owing to the protean manifestations of this NCSE (confusion, altered mental status, non-responsiveness and dazed stare with blinking), the diagnosis is usually not entertained and therefore frequently missed. The patient is wakeful but is dazed and may have frequent blinking. Patients with ASE usually have a history of generalised seizures, myoclonus or absence epilepsy. Sometimes, the status may start or end with a brief generalised seizure and the whole event may last for days. Well-recognised precipitants are withdrawal of benzodiazepines, head trauma and metabolic derangements. The EEG examination reveals continuous, generalised, symmetrical $3-\mathrm{Hz}$ spike-and-wave discharges. Intravenous diazepam, lorazepam or chlormethiazole usually terminates the status. Therefore, the EEG examination should always be considered in patients who have unexplained and persistent altered consciousness. ${ }^{1-3}$

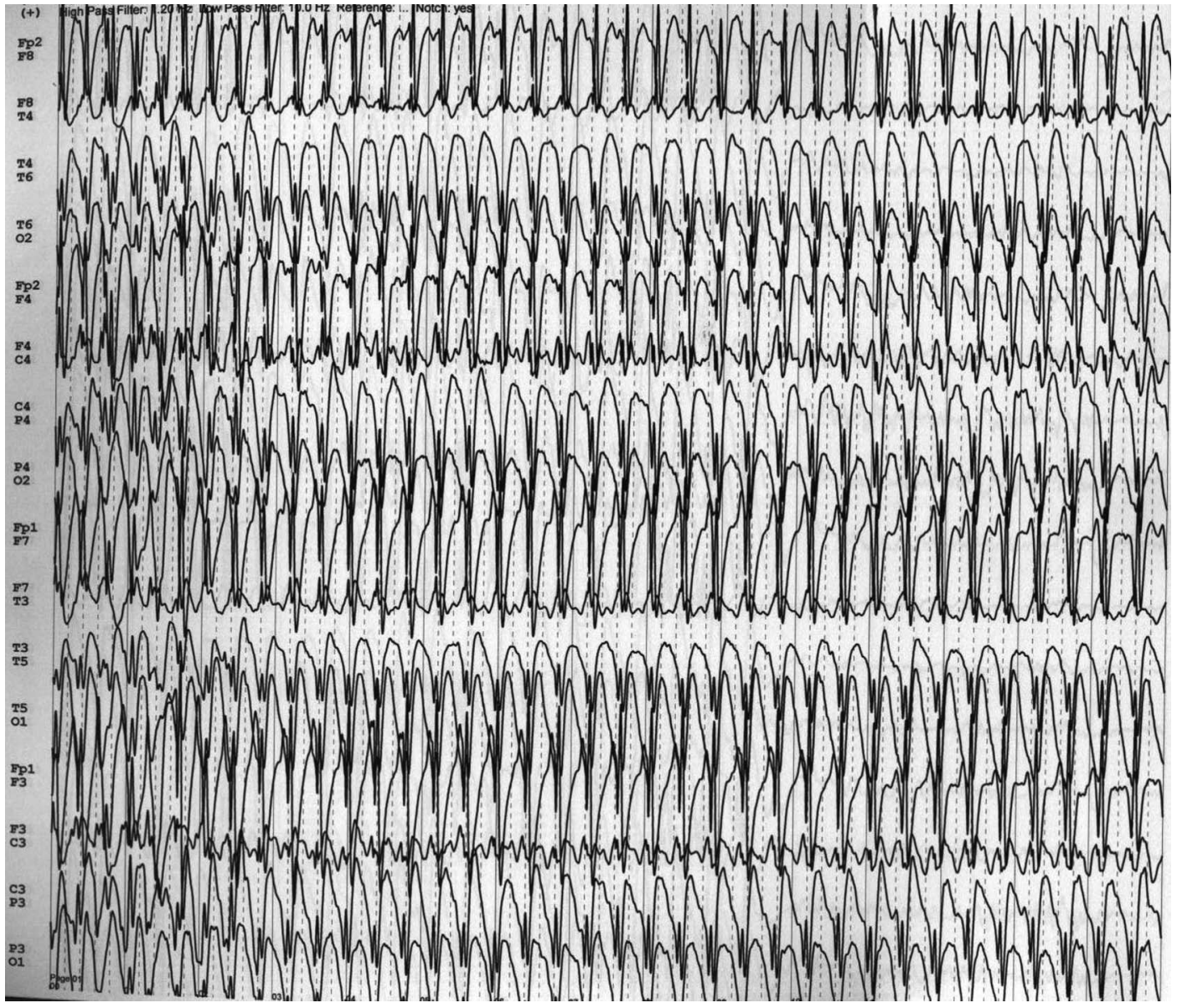

Figure 1 A scalp EEG examination using a standard 16-lead double banana protocol. Note the generalised symmetrical $3-\mathrm{Hz}$ spike-and-wave discharges. One of the interns rapidly skimmed the paper (without noticing that this was an EEG trace) and thought that this was a ventricular tachycardia! 


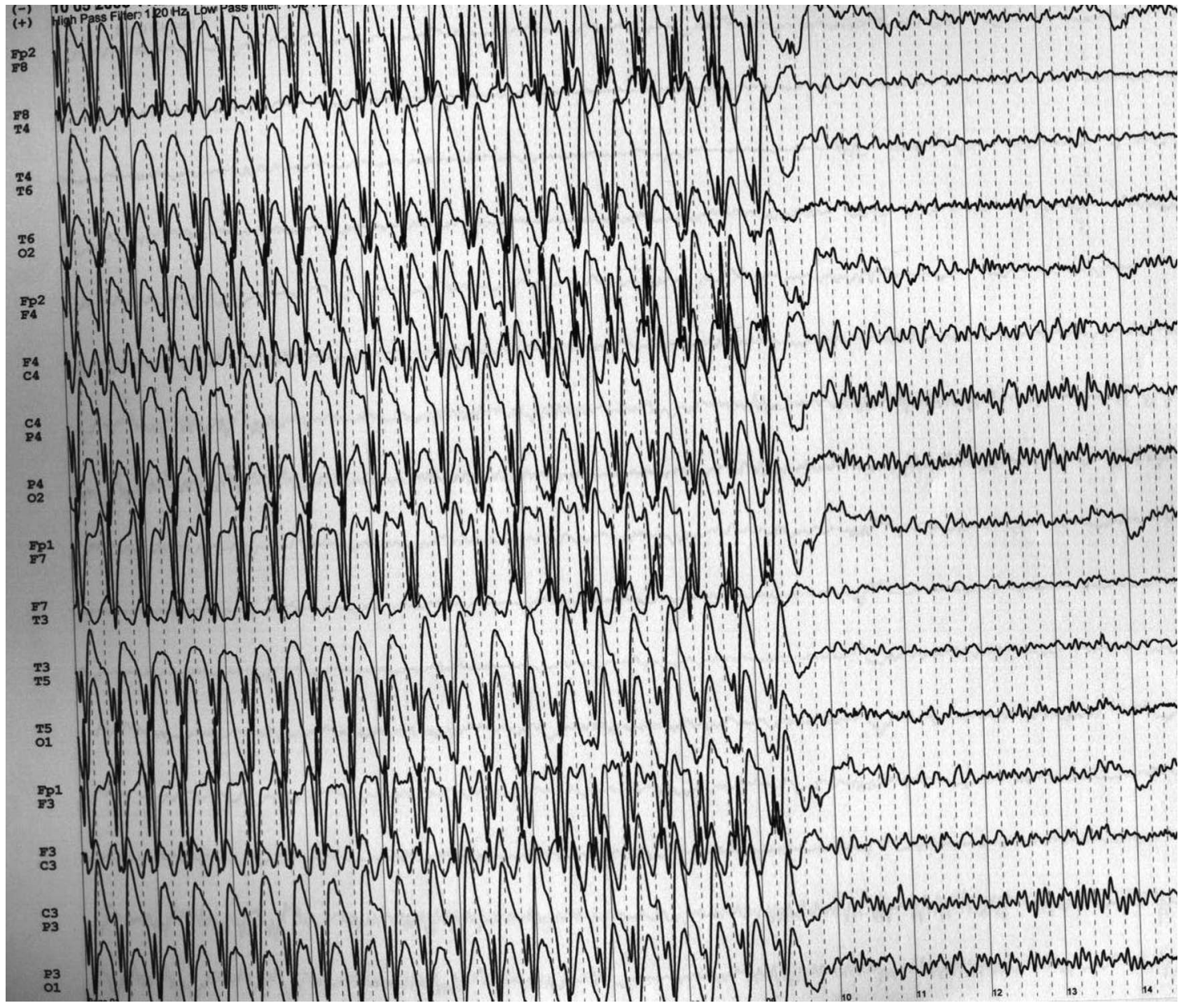

Figure 2 Within $1 \mathrm{~min}$ of intravenous diazepam infusion, the epileptiform activity terminates abruptly. This 11-year-old girl was given a diagnosis of acute psychosis before this EEG was performed. A psychosis in that age group without the influence of drugs is so rare that it should not be considered the first differential diagnosis.

\section{Learning points}

Owing to the protean clinical features and absence of gross motor manifestations, the diagnosis of absence status epilepticus is frequently missed.

- The diagnosis of non-convulsive status epilepticus, such as absence status epilepticus, should always be entertained in patients who present with otherwise non-explained, prolonged, confusional states or altered mental status, especially if a previous history of a seizure disorder is present.

- Electroencephalography usually confirms the diagnosis.
Competing interests None.

Patient consent Obtained.

Provenance and peer review Not commissioned; externally peer reviewed.

\section{REFERENCES}

1 Galimi R. Nonconvulsive status epilepticus in pediatric populations: diagnosis and management. Minerva Pediatr 2012:64:347-55.

2 Claassen J, Taccone FS, Horn P, et al. Recommendations on the use of EEG monitoring in critically ill patients: consensus statement from the neurointensive care section of the ESICM. Intensive Care Med. Published Online First: 8 May 2013. doi:10.1007/s00134-013-2938-4

3 Sutter R, Kaplan PW. Electroencephalographic criteria for nonconvulsive status epilepticus: synopsis and comprehensive survey. Epilepsia 2012;53(Suppl 3):1-51. 
Copyright 2013 BMJ Publishing Group. All rights reserved. For permission to reuse any of this content visit http://group.bmj.com/group/rights-licensing/permissions.

BMJ Case Report Fellows may re-use this article for personal use and teaching without any further permission.

Become a Fellow of BMJ Case Reports today and you can:

- Submit as many cases as you like

- Enjoy fast sympathetic peer review and rapid publication of accepted articles

- Access all the published articles

- Re-use any of the published material for personal use and teaching without further permission

For information on Institutional Fellowships contact consortiasales@bmjgroup.com

Visit casereports.bmj.com for more articles like this and to become a Fellow 